\title{
Pedagogical rehabilitation of syllogomania as a type of deviant behavior of senior citizens
}

\author{
Oksana Mosina ${ }^{1, *}$, Oksana $\mathrm{Us}^{1}$, and Anna Lakreeva ${ }^{1}$ \\ ${ }^{1}$ Kuban State University, 178, Sormovskai av., 350910, Krasnodar, Russia
}

\begin{abstract}
Syllogomania is a deviant behavior recognized as socially dangerous, since gathering turns the territory of a syllogoman into a dump of unnecessary things. Unsanitary conditions are difficult to be eliminated. The pathological gathering is studied by psychologists and medical psychiatrists. The research subject is behavioral deviations in old age associated with personality characteristics of the syllogoman; situations that initiated the development of this deviant behavior were described, the reasons for the development of syllogomania and the role of old things for elderly persons were analyzed. Recommendations for implementing pedagogical rehabilitation measures for elderly people prone to pathological gathering were given. The main task of pedagogical activities is reintegration of the elderly syllogoman into society, restoration of lost ties and resocialization. The leading areas of rehabilitation are restoration of the social status, family and social rights and obligations, self-care and hygiene skills, medical work.
\end{abstract}

\section{Introduction}

The social conflicts of modern society actualize the need to develop a rehabilitation system for the elderly, since the problems of socialization of the retired are becoming increasingly prominent. New formats of modern society initiate new types of adaptation and contribute to the development of various types of obsessive behavior. Collection and storage of unnecessary things occupies a significant place. Limited socio-cultural contacts prevent issues of life support, self-realization, etc. from being solved. The issues of rehabilitation of elderly people fall into the category of the most demanded.

In order to study the problem of pedagogical rehabilitation, it is necessary to develop the conceptual apparatus: categorical concepts of "syllogomania" and "pedagogical rehabilitation".

In the second half of the twentieth century, psychiatric aimed at studying senile dementia as a detachment from the outside world were published. The most evident features of the are collection of unnecessary, obsolete things, sloppiness, indifference to the state of the territory of residence, a refusal to observe hygiene standards, etc.

However, the symptoms described by modern scientists have been observed in humans even before the twentieth century. The most prominent representative of syllogomania is a famous character described by N.V. Gogol: “... this landowner had a courtyard, which was prepared for stocking all kinds of wood and utensils, never been used, jugs with stigmas and without stigmas, twin brothers, baskets, schoolchildren, where women put their lobes and other squabbles, baskets of thin bent aspens .... He walked along streets of his village, looked under the bridges, crossbeams and collected everything that came across to him: an old sole, a woman's rag, an iron nail, an earthenware pot... it happened that a passing officer lost a spur - this spur instantly went to a wellknown pile; if a woman left a bucket, he he took it. In his room, he lifted everything he saw from the floor: wax, a piece of paper, a feather, and put all these things on the bureau or on the window-sill" [1].

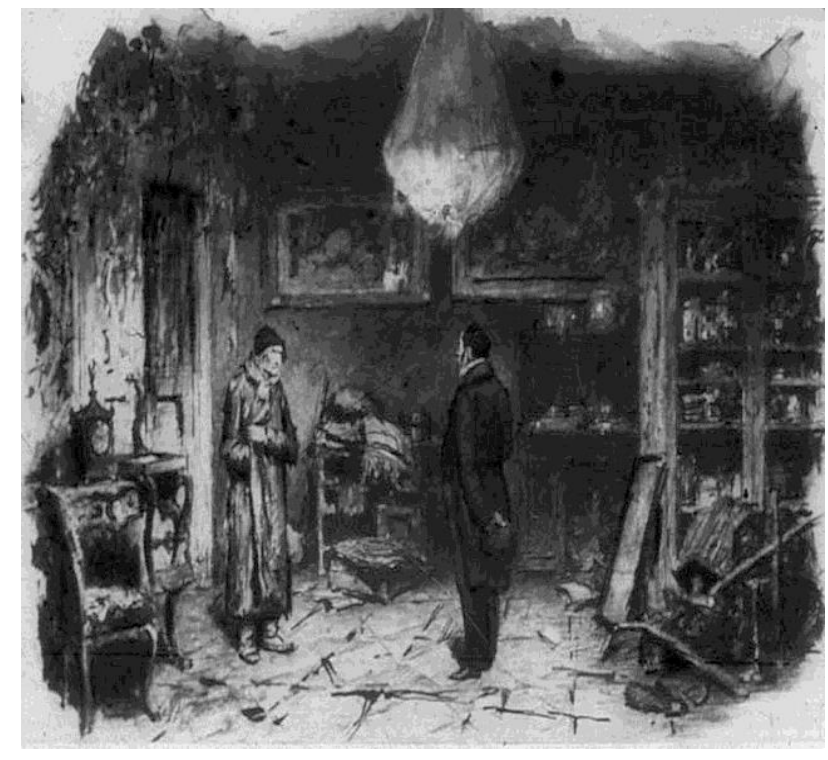

Pic 1. A hoarder

The artistic image created by Gogol reflects painful manifestations of a pathological disease. According to

\footnotetext{
* Corresponding author: kuvshinovaoa@mail.ru
} 
the European statistics, pathological collection, regardless of age, affects 2-5 percent of the population. There is no gender component in this collection, men and women are equally susceptible to pathological gathering [2].

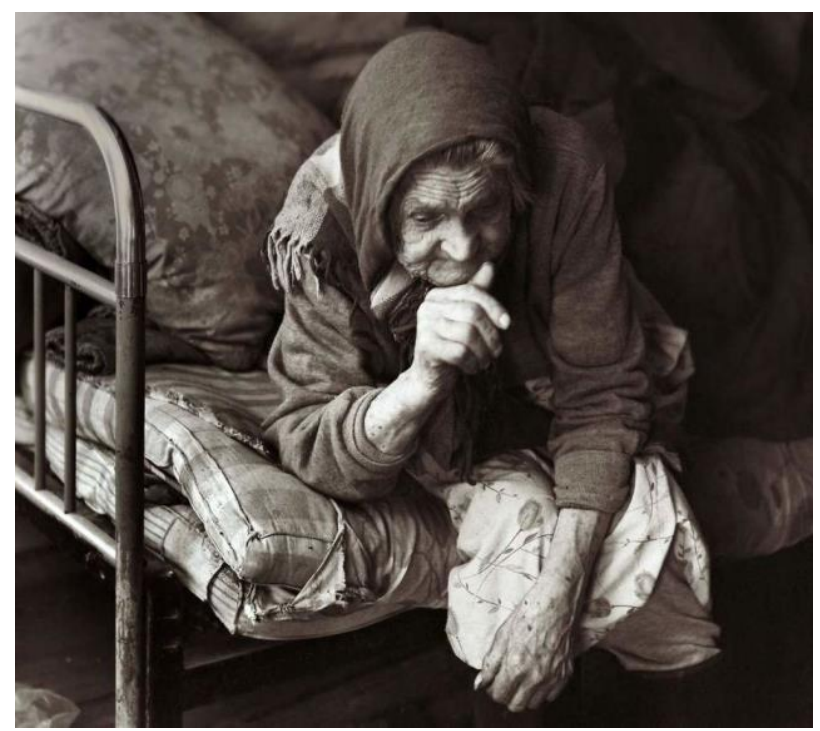

Pic 2. Abandoned elderly

These deviations are referred to as "syllogomania" - a type of obsessive behavior involving collection of household items in such quantities that prevent the use of the territory of residence for its intended purpose.

Manifestations of syllogomania deteriorate relations with relatives, making the individual indifferent to the needs of others, aggressive and overly suspicious. In this regard, works aimed at studying causes that affect the emergence and development of various types of deviant behavior are promising. In the psychological and pedagogical discourse of the beginning of the $20^{\text {th }}$ century, much attention is paid to vital activities of elderly people (M. Zyskina, M. Elyutin, T. Kozlova, A. Soloviev) $[3,4,5]$.

Researchers deal with a new understanding of old age in the context of the demographic transformation of society. However, the problems of behavior deviations in elderly people are understudied.

Most Russian researchers consider syllogomania as a social problem related to social isolation, violation of interpersonal relations, etc. These problems cannot be only social. They can be caused by the psychological development, peculiarities of upbringing which can aggravate existing psychological problems and stimulate the deviant behavior [6].
Among causes of behavioral disorders, there are intragenerational family conflicts; loss of social significance; anxiety associated with memories.

The purpose of the present study is to determine measures for pedagogical rehabilitation of syllogomania as a type of deviant behavior in old age.

\section{The objectives are as follows:}

- theoretical study of the importance of old things for elderly persons;

- identification of sources of syllogomania;

- determination of key motives for pathological gathering of unnecessary things by elderly people.

\section{Materials and methods.}

The materials are significant for a detailed study of features of the development of deviant behavior in old age. The territory of Krasnodar was an experimental base.

In accordance with the objectives, the following groups of methods were used:

- theoretical: analysis of sociological, psychological and pedagogical literature;

- empirical: selective surveying which includes observation of elderly people prone to syllogomania and their neighbors;

- analytical: research of speech activity products, isolation and grouping of key phrases.

\section{Results and discussion.}

The roles of the elderly generation within the family and in society are not subject to the influence of time [7].

However, most researchers emphasize some traditional positions transmitted from generation to generation. The most interesting ones are behavioral manifestations of behaviors of "King Lear", "sunset effect", "Plyushkin", etc.

Age-related psycho-emotional stagnation does not allow the elderly to be mobile and dynamic. Against the background of the disruption of the order of events, the elderly disrupts the usual rhythm of life, is under the psycho-emotional stress, and feels uselessness.

In this state, the elderly can concentrate on the material side of stability, immutability over time, the material situation, stability of household utensils. Isolation of the individual living space, personal autonomy can be associated with a range of familiar things - household items, belongings, rather than antiques as objects of social respectability.

According to this there is a chance to represent signs of a syllogoman by a diagram. 


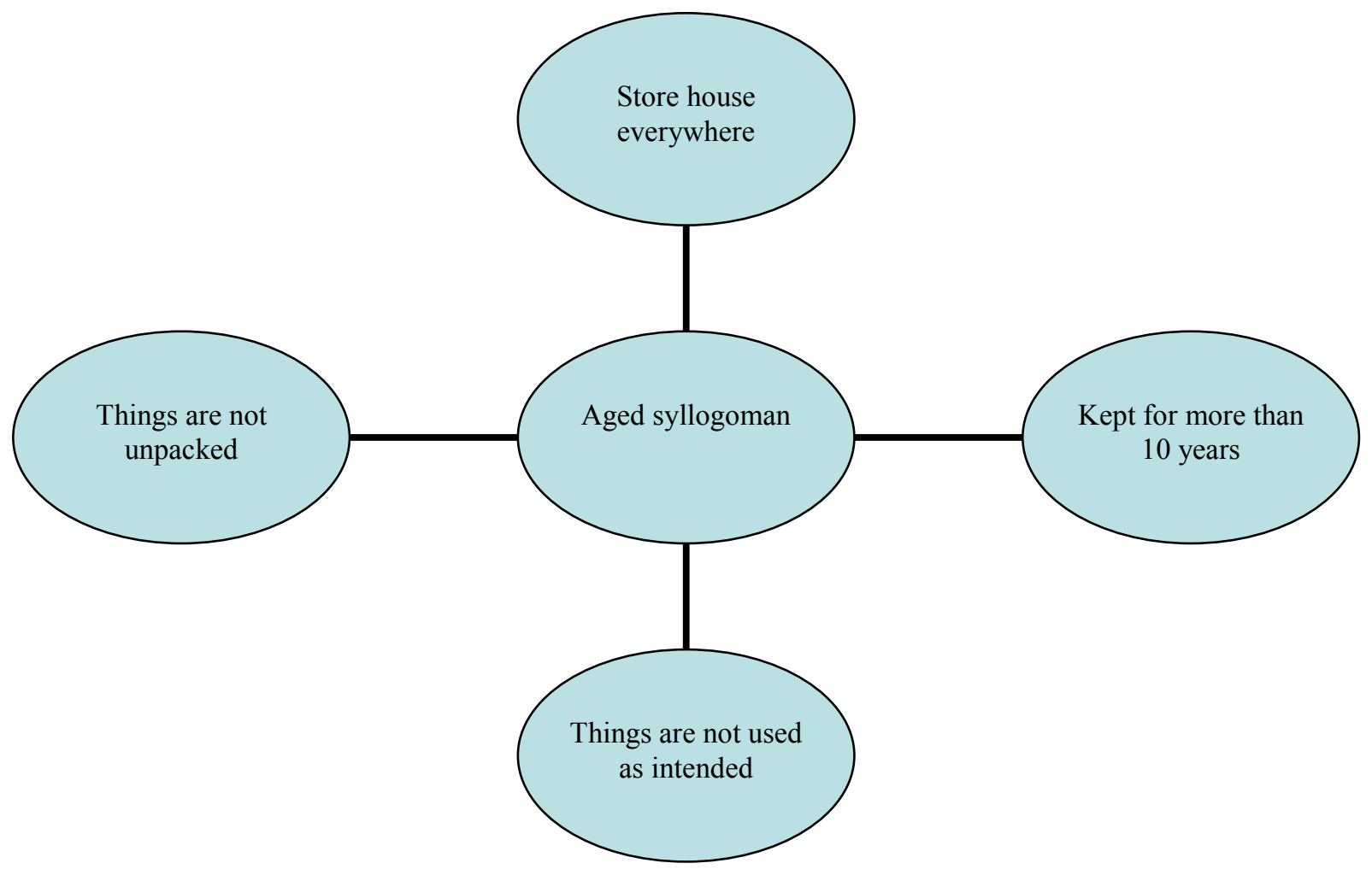

Pic 3. Signs of an aged syllogoman

Over time, clothing stability can go to the level of identification of an individual with surrounding things, they become dependent on them. In the context of dependence, assessment of the value of surrounding things, their significance and symbolic functions are distorted. These processes are associated with the loss of a sense of security and development of feelings of anxiety or even depression.

One of the problem areas of the functional load of familiar things is their memorial function which reflects memories and significant events. Trying to reproduce these events, the elderly can cross a line of necessity and begin to collect things that seem memorial. They store them in their houses or in the courtyard.

A pilot study on the problem of syllogomania in old age was conducted in the Pashkovsky rural district of Krasnodar; 12 people aged 60-82 and 18 neighbors were surveyed. In this district, there are a lot of private households which facilitates the research task.

The survey of neighbors showed that "gathering" and "clogging of free space" are a behavioral model of elderly neighbors. They go to garbage bins and sort garbage out for several hours. Discarded items are carefully sorted out, "necessary" items are selected and brought to the territory of their residence. This behavior has been recorded for 24 months or more. The space of residential buildings is already full.

An oral survey of elderly people who collect discarded and old things was carried out. They were asked about the purpose of gathering; the value of collected things in their life; functional load of collected things. The interviewer asked clarifying questions that do not go beyond the scope of the research tasks.
It was possible to conclude that the source of syllogomania in elderly people was family breakdown or destruction of internal connections. The usual rhythm and lifestyle were violated as a result of heavy losses related to the loss of a loved one and a place of residence which formed a non-traditional mechanism of selfdefense in a new space.

One more cause of pathological gathering is a lack of the "family artifact environment" [8]. The young generation strives to meet challenges of the time, destroy old things as symbols of bad taste of the older generation, not realizing that elderly people associate old things with past events.

Priority positions (more than $50 \%$ of positive answers) are shown in Table 1.

Table 1. A survey of elderly syllogomania addicted persons.

\begin{tabular}{|c|c|c|c|}
\hline $\begin{array}{c}\text { Source of } \\
\text { deviant } \\
\text { Behavior }\end{array}$ & Compensator & $\begin{array}{c}\text { Functional } \\
\text { Load }\end{array}$ & \% \\
\hline $\begin{array}{c}\text { Family } \\
\text { situation of } \\
\text { breakdown }\end{array}$ & $\begin{array}{c}\text { Compensation } \\
\text { for loneliness }\end{array}$ & $\begin{array}{c}\text { Filling empty } \\
\text { space, } \\
\text { stagnation } \\
\text { communication }\end{array}$ & 67 \\
\hline $\begin{array}{c}\text { Destruction } \\
\text { of internal } \\
\text { relations }\end{array}$ & $\begin{array}{c}\text { Similarities to } \\
\text { Memorial } \\
\text { Things }\end{array}$ & $\begin{array}{c}\text { Accumulation } \\
\text { of memories } \\
\text { and gratitude to } \\
\text { elderly people } \\
\text { from relatives }\end{array}$ & 61 \\
\hline $\begin{array}{c}\text { Artifacts of } \\
\text { the social } \\
\text { environment }\end{array}$ & $\begin{array}{c}\text { The role of } \\
\text { semantic } \\
\text { guidelines }\end{array}$ & $\begin{array}{c}\text { Denial of old } \\
\text { age as a life } \\
\text { limit }\end{array}$ & 59 \\
\hline
\end{tabular}


A compilation of the answers allowed us to identify several large groups of motives that stimulate the development of syllogomania.

Filling the territory of residence with things thrown away by other people is a result of an attempt to compensate for the feeling of loneliness associated with an open, empty space.

Old things are collected according to the principles of involvement, similarities with memorial things, which allows a person to talk to them during the communicative stagnation or to excite old memories.

Things are semantic guidelines, symbols compensating for heavy losses suffered.

Collected things reflect procrastination typical for elderly people. This activity encourages the process of postponing the decision, initiating the idea that he can make other decisions.

The clutter of a living space with things creates illusion of its expansion and relevance. In order to perform any activity, you must first find a lever - a thing to perform this activity, which stimulates motor activities and creates a semblance of useful activity. At the same time, search activities create a semblance of normalized everyday home practices.

A pile of things is a symbol of the presence of an elderly person inside and outside his living space. Old thins replace events of being, help hide visual images of the transforming world, create a shadow of stability.

Old things act as a regulator of communication between generations. An elderly person expects that after his death, these things may be needed by children and grandchildren and they will remember and thank him for his prudence and frugality.

Things are a proof that old age is not the limit of life. The old thing, though broken, can do a lot of good. And if it is repaired, it will become like new and even better. An elderly person associates himself and these things, thereby transmitting the possibility of continuing his life in old age. The more things, the more evidence.

Thus, the analysis of research results allowed us to draw a number of reasonable conclusions. Gathering old things, the elderly overcomes the lack of attention, communication, socially significant environment, emotional stability. In most cases, syllogomania is initiated by the consumer attitude towards the elderly from the immediate environment - relatives, family members - which causes loss of the utilitarian meaning of the thing thrown away and its perception as own social death. Collection is regarded as an act of mercy, deliverance from momentary death, an increase in the duration of its life.

Hoarding influences the pathological collector and his family members. They violate sanitary safety rules, cause epidemiological infections, destabilize the relationship system, cause constant quarrels, material and financial damage, create dangerous living conditions for children, etc. In addition, pathological collectors experience difficulties in assessing objective reality and their psycho-emotional state.

The need for rehabilitation measures is beyond doubt. Points of view of pedagogical science must be included into the educational process which must be structured and create favorable social conditions. The objective of this process is integration into society of the elderly, and normalization of communication.

The orientation of pedagogical rehabilitation should be aimed at a specific person. The rehabilitation specialist should have special knowledge about the specifics of the elderly, possibilities of development of the elderly, specifics of problems and factors that act as incentives for the formation of deviations. At the same time, rehabilitation activities should include the closest social environment of the syllogoman. The coverage of the spheres of life should also be comprehensive - these are household, family, leisure and other spheres that affect the transformation of attitudes to oneself, the situation that has developed and own behavior.

The rehabilitation program should be based on the analysis of rehabilitation processes, social skills mediated by the principles of partnership: interaction and trust. The adequate relationship "rehabilitation specialist - syllogoman - immediate social environment" is also significant [9].

It is important to understand the need to involve the syllogoman in various activities: group classes held in social centers. Due to the specifics of behavioral cliches, personality-oriented trainings should be effective: "Letters to Yourself," "Health and Pain," "The Most Vivid Memory of Childhood," "Melt Resentment," "Three Questions for My Interlocutor," "One Day of an elderly person", "Compliments to oneself are compliments to others" [10] built on the basis of an indepth study of own "I" and adoption of own life path.

Having realized the problem that stimulates behavioral deviations, it is necessary to include the syllogoman in the communicative circle, talking with his peers who have experienced similar losses or who have been in similar life situations. Initial conversations should be narrative, exclude conflicts or debates. Only after the syllogoman has been included into the permanent communicative field, he can be involved in mass events as part of the reference group.

One more condition for the pedagogical rehabilitation is rehabilitative measures. The presented principles are a theoretical and practical basis for solving rehabilitation problems.

\section{Conclusion}

The main task of pedagogical rehabilitation is reintegration of an elderly syllogoman into society, restoration of lost ties, re-socialization. The leading areas of rehabilitation include restoration of the social status, legal capacity in the eyes of family members and the social environment, social and communication skills, self-care and hygiene skills, medical work.

The analysis suggests that restoration of family ties may have a positive effect on the state of the elderly syllogoman. The teacher can determine a new hobby, identify communicative problems, the depth of the state of loneliness and insecurity. Such measures as switching attention, anti-examples can be used for the rehabilitation. Relatives can include the elderly 
syllogoman in the sorting process. Used things must be sorted out and removed, those things which are not in demand should be given to the poor.

The article analyzed the problem of syllogomania in the context of pedagogical knowledge which is not traditional. It does not pretend to be complete, but opens research prospects.

\section{References}

1. N.V. Gogol, Dead souls, Retrieved from:http://www.klassika.ru/read.html?proza\%2Fgogol $\% 2$ Fdushi.txt\&page $=22$ (2019)

2. M. Marcos, MC. Gomez-Pellin, $A$ tale of $a$ misnamed eponym: Diogenes syndrome, Int. J. Geriatr Psychiatry, 23, 9 (2008)

3. M.E. Elyutina, Marriage relations in old age, Socis, 11, 319, 83-92 (2010)

4. T.Z. Kozlova, On social status of pensioners, Socis, 5, 289, 135-136 (2008)
5. A.G. Solovyov, E.A. Mordovskiy, A.M. Vyazmin, Socio-demographic status of elderly and senile persons who died from alcohol-attributive condition in Arkhangelsk, Success of gerontology, 27, 1, 165-171 (2014)

6. G. Yu. Belyaev, Models of behavior as a matrix of education, Pedagogy, 10, 33-37 (2010)

7. O.A. Kuvshinova, Problems of the social construct of old age. Bulletin of Tomsk State University. Philosophy. Sociology. Political science, 1, 17, 24-30 (2012)

8. M. E. Elyutina, Elderly people and old things in everyday life, Socis, 7, 303, 101-108 (2009)

9. O. V. Kuchmaeva, E. A. Maryganova, O. L. Petryakova, A. B. Sinelnikov, On modern family and its educational potential, Socis, 7, 315, 49-55 (2010)

10. O. A. Mosina, R. A. Akhtanov, Strategic directions of modern gerontology, Modern problems of science and education, 3, Retrieved from:http://www.scienceeducation.ru/ru/ article/view?id=28806 (2019) 